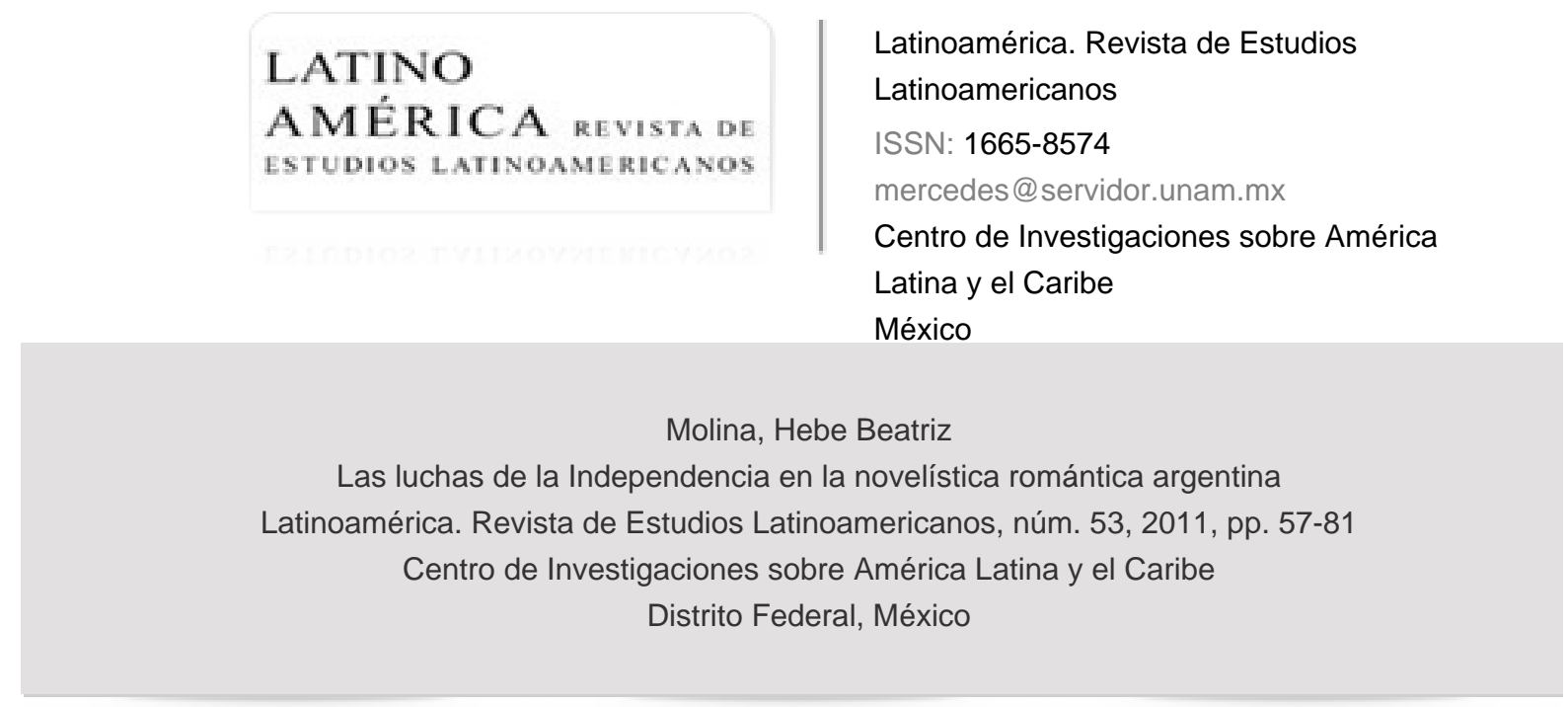

Disponible en: http://www.redalyc.org/articulo.oa?id=64021405004

- Cómo citar el artículo

- Número completo

- Más información del artículo

- Página de la revista en redalyc.org

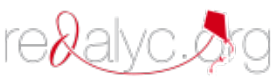

Sistema de Información Científica

Red de Revistas Científicas de América Latina, el Caribe, España y Portugal Proyecto académico sin fines de lucro, desarrollado bajo la iniciativa de acceso abierto 


\section{Las luchas \\ de la Independencia en la novelística romántica argentina}

Hebe Beatriz Molina*

Resumen: Entre 1840 y 1880, sólo siete novelas organizan la trama ficcional en torno de algún episodio de la gesta independentista. Pretendemos demostrar, desde la perspectiva de una poética histórica, que ha habido una condición intrínseca en el concepto de novela vigente en Argentina a mediados del siglo XIX, que ha limitado el interés de los novelistas por ese periodo. En los textos novelescos se dramatiza principalmente la opción "Patria 0 amada"; pero por el rasgo distintivo del género novela -idealización de sucesos cotidianos para fortalecer y promover las buenas acciones - se concentra la fuerza diegética en los asuntos del presente y se descuidan los del pasado.

PalaBRAS Clave: Novela histórica, Poética histórica, Política y literatura, Periodo de la Independencia, Literatura argentina.

ABSTRAC: Between 1840 and 1880 there are only seven novels about episodes from the independentist period. The aim of this paper is to prove that, from the perspective of historical poetics, there was an intrinsic condition in the concept of novel at use in the mid19th century which limited the authors' interest in that period. The novels dramatize mainly the option "Nation-Beloved"; but, considering the main characteristic of the genre - idealization of daily events to strengthen and promote good deeds - novels concentrate on the diegetic power of present events, and overlook those from the past.

KEY wORDS: Historical novel, Historical poetics, Politics and Literature, Independentist period, Argentine Literature.

\footnotetext{
Universidad Nacional de Cuyo, conIcET, Argentina (hebemol@ffyl.uncu.edu.ar).
} 
as luchas por la Independencia argentina se inician poco después del 25 de mayo de 1810, cuando se instituye en Buenos Aires la primera Junta Provisional de Gobierno, y se dan por concluidas con la batalla de Ayacucho, el 9 de diciembre de 1824. Este periodo incluye como hitos significativos la Declaración de la Independencia (el 9 de julio de 1816, en la norteña ciudad de San Miguel de Tucumán), el cruce de los Andes dirigido por el general José de San Martín y la campaña del Ejército Libertador en Chile y Perú (1817-1821).

Nos llama la atención que en el propio siglo xix las luchas independentistas hayan concitado la atención de muy pocos novelistas. Entre 1840 y 1880 se publican en Buenos Aires alrededor de un centenar de novelas y novelitas, con el estilo romántico propio de la época. De ese total sólo seis organizan la trama ficcional en torno de algún episodio de la gesta independentista: Soledad (1847), de Bartolomé Mitre; Una noche de boda (1854), de Miguel Cané; El isleño: episodio de la guerra de la Independencia (1857), de Manuel Romano; María de Montiel (1861), de Mercedes Rosas de Rivera; El capitán de Patricios (1864), de Juan María Gutiérrez, y El pozo del Yocci (1869-1870), de Juana Manuela Gorriti. A esta lista podemos agregar Capitán Vargas (ca. 1846), novela inconclusa y todavía inédita de Vicente Fidel López.

La literatura argentina decimonónica está particularmente vinculada a la historia política, que le sirve de motor. Por eso, sorprende este contraste entre la importancia histórica de las luchas independentistas y la escasez de textos novelescos referidos a esas hazañas y a sus héroes. Si dejamos de lado las razones fundadas en las vicisitudes políticas y adoptamos la perspectiva de una poética histórica, ${ }^{1}$ podemos presuponer que ha habido una condición intrínseca en el concepto de novela vigente en Argentina a mediados del siglo xIx que ha limi-

1 Según Michał Głowinski, la poética histórica analiza el proceso histórico-literario que explica la consideración de la obra literaria en cuanto fenómeno social durante un determinado periodo, teniendo en cuenta las normas o reglas intersubjetivas gracias a las cuales el escritor sabe cómo componer su texto para que lo entienda el lector: Estas normas pertenecen a un sistema literario sincrónico específico, si bien son frecuentemente heredadas de la tradición frente a las normas aparecen las excepciones, que permiten la evolución literaria. 
tado el interés de los novelistas por ese periodo histórico. Esta hipótesis nos obliga a presentar, primero, un panorama del sistema literario argentino decimonónico, configurado en torno al nacimiento de la Patria, para ubicar en él las funciones socioliterarias asignadas a la novela; luego, la organización narrativa de los textos, a fin de analizar - aunque sea someramente- la axiología que se infiere de tal estructura y que explicaría ese (aparente) desinterés por las luchas independentistas.

\section{LA NOVELA EN EL SISTEMA LITERARIO}

DE MEDIADOS DEL SIGLO XIX

La defensa de Buenos Aires ante las pretensiosas invasiones inglesas (en dos ocasiones: 1806 y 1807) y, luego, las campañas militares contra las tropas españolas (desde septiembre de 1810) fomentan un sentimiento de amor a la patria, por medio del cual se pretende lograr la unidad de objetivos. La Patria que reúne voluntades resulta entonces el espacio donde se quiere vivir en libertad. El patriotismo - por ser un estado afectivo- alienta a los literatos, especialmente a los poetas: con sus odas, marchas y cantos dedicados a los héroes o a las victorias, provocan una respuesta también afectiva de los ciudadanos hacia esa nación de la que van tomando conciencia. Pero esta literatura todavía no manifiesta un estilo identitario: los poemas se escriben siguiendo los modelos neoclásicos españoles.

El tema de la Patria es reavivado por los jóvenes de la Generación de 1837, quienes - a través de los artículos de costumbres y del ensayo- proponen medidas concretas para alcanzar la independencia cultural que estaba faltando. Esteban Echeverría, maestro de esa Generación, insta a argentinizar la literatura tomando como tema el desierto, o sea, el espacio casi despoblado de la llanura pampeana; él mismo da el ejemplo con su poema "La cautiva" (1837). Pero, hacia 1840, la tiranía de Juan Manuel de Rosas cambia el rumbo del desarrollo literario, pues lanza al exilio a buena parte de los intelectuales y se impone como tema prioritario, incluso en los poemas dedicados a recordar la fecha "patria"; por ejemplo, "A Rosas, el 25 de mayo de 1843", de José Mármol. Este mismo autor des- 
cubre las ventajas de la novela como instrumento de transmisión ideológica y las aprovecha de tal modo que su Amalia $(1851-1852,1855)$ ha sido considerada - hasta avanzado el siglo Xx - testimonio fidedigno de la época rosista. ${ }^{2}$

La escritura de novela surge por imposición del sistema literario de lectura, importado de Europa. Este género atrae a todos los lectores, hombres y mujeres, quienes tienen a su disposición (y al alcance de su bolsillo) una abundante oferta de textos traídos del Viejo Continente, la mayoría de origen francés (en su idioma original o traducido), pero también muchos otros de autores españoles. Novelas sentimentales, de aventuras, costumbristas e históricas se multiplican en los folletines de los también cuantiosos periódicos porteños o en fascículos que se entregan semanal o quincenalmente, previo pago de suscripción. No obstante, este género suscita una valoración dual; por un lado, es criticado del mismo modo que en España, a causa de su presunta inmoralidad, ya que tratan conflictos amorosos indeseados (seducción, coquetería, adulterio y todo tipo de infidelidades y abandonos) y reflejan costumbres extranjeras (es decir, extrañas), diferentes de los hábitos perfectivos que se postulan como ideales para una sociedad que está edificando su nacionalidad; por otro lado, es apreciado como costumbre beneficiosa por promover el ejercicio intelectual tanto en las mujeres - destinatarias preferidas, convocadas explícitamente por todos los autores-como en aquellos varones dedicados exclusivamente a tareas mercantiles - destinatarios indirectos-.

Poco a poco, la escritura de novelas empieza a ser considerada una labor muy digna y una responsabilidad ciudadana, sobre todo después de la caída de Rosas (1852). La nación parece estar ya configurada en República y, por ello, necesita una sociedad nueva, basada en los valores cívicos. En este contexto, la novela es promovida como un instrumento educativo válido porque su contenido interpreta la realidad cotidiana -la vida privada o familiar (la vida pública le incumbe a la historia y a la épica) - y, gracias a su estilo sencillo, resulta una

2 Una síntesis del debate en torno al valor histórico y literario de esta novela puede verse en Beatriz Curia, "Amalia, novela histórica", en Revista de Literaturas Modernas, núm. 16, 1983, pp. $71-81$. 
lectura amena: instruye deleitando, que es como decir "sin que se den cuenta los lectores".

Bartolomé Mitre - en el prólogo de Soledad, uno de los primeros metatextos argentinos-le asigna una función civilizadora y un lugar en la evolución de los pueblos: pasado el periodo bélico inicial, cantado por los poetas, se debía pasar a la etapa de progreso social, para lo cual la novela era la forma más apropiada:

Es por esto que quisiéramos que la novela echase profundas raíces en el suelo virgen de la América. El pueblo ignora su historia, sus costumbres apenas formadas no han sido filosóficamente estudiadas [... ]. La novela popularizaria nuestra historia echando mano de los sucesos de la conquista, de la época colonial, y de los recuerdos de la guerra de la independencia. [...] y haria conocer nuestras sociedades tan profundamente ajitadas por la desgracia, con tantos vicios y tan grandes virtudes, representandolas en el momento de su transformacion, cuando la crisálida se transforma en brillante mariposa. Todo esto haria la novela, y es la única forma bajo la cual pueden presentarse estos diversos cuadros $\tan$ llenos de ricos colores y movimiento. ${ }^{3}$

Obsérvese el uso del condicional simple, que descubre la realidad de ese momento (1847): la novela no es todavía un género instalado sino potencial; y los temas sugeridos abarcan tanto el pasado como el presente, para proyectar la sociedad a un futuro "brillante". Como Mitre, los otros novelistas pioneros -Vicente Fidel López, Miguel Cané, principalmente- exponen a través de tratados de retórica, debates periodísticos, publicidad y peritextos una poética de la novela, que compartirán con sus lectores. ${ }^{4}$ A partir de la definición elaborada por López en su Curso de Bellas Letras (1845): "idealizacion de un suceso doméstico, narrada con tono sencillo i vulgar; para interesar la imajinacion, promover afectos morales, i fortalecer los buenos principios de nuestra conducta

3 Bartolomé Mitre, Soledad: novela original, nota preliminar de Juan Millé y Giménez, Buenos Aires, Universidad de Buenos Aires, 1928, pp. 89-168; pp. 94 y 95. En ésta y en todas las citas respeto la grafía original.

4 He analizado estos asuntos en los estudios consignados en la "Bibliografía". 
privada", 5 se generaliza la exigencia de moralidad, verosimilitud y amenidad como características genéricas ineludibles. A mediados del siglo xix las novelas se multiplican; la mayoría de las historias son triviales y poco originales, pero la nota distintiva en casi todas ellas es la argentinización o americanización de los espacios y las referencias al pasado histórico reciente.

Entre las modalidades narrativas, la novela histórica es la más apreciada porque se la considera un complemento de la historia: en la trama ficcional puede mostrarse la otra cara de las personalidades destacadas, su faceta cotidiana y familiar, y de este modo reconstruirse costumbres y situaciones privadas, con las cuales se llega a conocer la "verdad completa". ${ }^{6}$ Las propias corrientes historiográficas vigentes a mediados del siglo xIx aprobaban esta simbiosis entre historia y ficción, y los textos de Walter Scott servían de modelo tanto a historiadores como a novelistas. Los escritores, no obstante, enfrentan un dilema: qué momentos del pasado reconstruir. Por una parte, no pueden alejarse mucho de su presente, como hace Scott, porque no conviene a un país en vía de independencia resaltar los tiempos más pretéritos, esto es, los de la Conquista y de la Colonia.? Sólo tres mujeres, Eduarda Mansilla de García, Rosa Guerra y Juana Manuela Gorriti, se dedican a revivir las leyendas más antiguas, como la de Lucía Miranda o la de los tesoros escondidos de los incas. Por otra parte, el pasado más inmediato, esto es, el periodo de las guerras civiles (décadas de 1820 a 1850) -con su carga de muertes y de exilios - afecta personalmente a los escritores que se vuelve tema recurrente; Amalia se convierte en prototipo de una serie de novelas antirrosistas, con las que se pretende no sólo estigmatizar al tirano ya vencido, sino sobre todo prevenir contra el surgimiento de nuevos tiranos. El lapso entre 1810 y 1820 queda, pues, disponible.

5 Vicente Fidel López, Curso de Bellas Letras, Santiago de Chile, Imprenta del Siglo, 1845, p. 297. Cfr. Hebe B. Molina, "Una poética argentina de la novela: Vicente Fidel López (1845)", en Hofstra Hispanic Review, núms. 8-9, Nueva York, verano-otoño, 2008, pp. 18-32.

6 Vicente Fidel López, "Carta-prólogo", en La novia del hereje o La Inquisición de Lima, Buenos Aires, Imprenta de Mayo, 1854, p. 10.

7 Cfr. Raúl Ianes, De Cortés a la huérfana enclaustrada: la novela histórica del romanticismo bispanoamericano, Nueva York, Peter Lang, 1999. 


\section{LOS PATRiotas, ENTRe la PATRIA Y la AMAdA}

Desde el comienzo del proceso revolucionario criollo, el carácter de héroe, prócer o ciudadano ilustre se otorga sólo a algunas personas, por las virtudes y los méritos manifestados en su accionar, por los servicios que presta a la Patria, sin que importe su origen, su "cuna"; es decir, será un patriota todo aquel que participe en las lides de la políica o de la guerra. Con frecuencia pueden leerse afirmaciones como ésta, extraída de El isleño: "Julian no es un hombre sin títulos: está condecorado con el honorífico título de teniente de los ejércitos de la patria, resultado de su primera prueba en un combate contra los enemigos donde luchó bizarramente".

Los novelistas prefieren a los militares jóvenes, aquellos que se destacan tanto en los campos de batalla como en las lides amorosas; pero, dado que las acciones bélicas no son atractivas para las potenciales lectoras, los escritores centran la atención en los conflictos amorosos. El modelo romántico de novela histórica así lo establece también: la trama se configura en torno a un idilio que la guerra interrumpe o, por lo menos, altera. Los patriotas protagonistas enfrentan una opción terminante: cumplir con el deber patriótico o concretar la relación amorosa. Comparando las estructuras narrativas y axiológicas de las novelas, se observa que los escritores varones resuelven ese dilema de distinta manera que las mujeres.

El patrón de la novela patriótica lo establece Juan María Gutiérrez en $E l$ capitán de Patricios (1864), ${ }^{9}$ texto al que el propio autor califica de "cuento", tal vez por la simplicidad de la trama argumental: un joven innominado, capitán

8 Manuel Romano, El isleño: episodio de la guerra de la Independencia, Buenos Aires, Imprenta Americana, 1857, p. 56. No se conocen datos biográficos de este autor.

9 Gutiérrez habría escrito esta novela durante su estadía en el Piamonte, hacia 1843. Es publicada por primera vez en tres entregas en el Correo del Domingo, Buenos Aires, abril, 1864, y luego, ese mismo año, en un volumen de 64 páginas, por la Imprenta del Siglo. Juan María Gutiérrez es uno de los intelectuales argentinos más importantes de siglo xix por su actuación en el periodismo, la educación superior, la crítica literaria y diversas instituciones culturales, además de su participación política.

${ }^{10}$ Juan María Gutiérrez, El capitán de Patricios, Buenos Aires, Imprenta del Siglo, 1864, p. 2. 
del Regimiento de Patricios, conoce e inmediatamente se enamora de María, una mujer muy bella y culta. Apenas declarado el amor mutuo, el militar debe partir con el ejército hacia el Alto Perú (Bolivia). Ella promete no amar más que al Capitán o a Dios. El hombre muere en una emboscada en Humahuaca; entonces, María ingresa a un convento.

El interés de esta novela radica en una configuración de los roles sociales masculinos y femeninos, en torno a las luchas independentistas, que resulta paradójica. El Capitán se muestra melancólico pues pelear por la patria y el honor no lo satisfacen plenamente, mientras que el amor por la joven lo apasiona de tal modo que hasta modifica, dulcificando, sus relaciones con los subordinados. María, en cambio, educada por un tío sacerdote sobre todo mediante la lectura de los clásicos, no sólo toma la iniciativa de declarar sus sentimientos al Capitán, sino que también decide la suerte de la pareja ajustando la opción: cambia la alternativa Patria o amor por bonor o deshonor:

-Capitan, le dijo, esa órden despedaza en dos nuestros corazones convertidos en uno solo [...]; pero es preciso obedecerla. Si tuviera vd. la cobardia de desoir la voz de la Patria y de las obligaciones, no seria vd. para mí un objeto de cariño sinó de aversion. Nuestro amor debe tener por fundamento la estima y esta se alimenta con actos virtuosos. Parta vd. Capitan: deme vd. frecuentes noticias de sus triunfos y ascensos, mientras yo pido al cielo que le guarde á vd. de todo peligro. ${ }^{11}$

La defensa armada de la Patria, que garantiza la libertad a los pueblos, produce a los jóvenes - en cambio - un beneficio individual, poco altruista por cierto: la gloria y la fama en la carrera del honor. Así, mientras la mujer reza y espera, el varón debe triunfar y ascender para hacerse digno de su amor. Las exigencias sociales son, pues, mayores para los patricios que para las amadas. El tío sacerdote expone este código de honor a través de la crítica a un texto que ha cantado María:

${ }^{11}$ Ibid., pp. 47 y 48. 
[... ino es verdad Capitan, que nada tiene de propio el argumento de la letra de ese romance $[. .$.$] ? Ese caballero cruzado que va á la guerra de Palestina, llora$ demasiado la separacion de la mujer que ama, siendo asi que la gloria y la relijion que son dos hermosuras eternas, le piden el auxilio de su espada. Podia vd. encargarse de correjir esos versos, apropiándolos á las circunstancias: vd. es militar y poeta y se desempeñará á nuestra satisfacción. ${ }^{12}$

El Capitán, con la entrega de su vida, ajusta el poema a las exigencias patriotas. La Patria, que "tiene un altar demasiado ancho [como] para que se contente con pocas víctimas", ${ }^{13}$ separa lo que ya ha unido. En el primer encuentro fortuito entre los jóvenes, ella ha lucido un vestido blanco con cintas celestes y el Capitán ha interpretado la casualidad como predestinación: "Los colores del vestido de vd. son los de mi bandera, y por consiguiente mi honor y mi deber estan en este momento bajo su sombra" ${ }^{14}$ La elección de María como posible esposa perfecta se fundamenta en las cualidades de su carácter, valoradas según los roles sociales asignados a las patricias: "era la espresion de una voluntad jenerosa, y de una constancia digna de la criatura destinada á hacer feliz al esposo y buenos ciudadanos á los hijos". 15

María también ejerce la libertad de elegir marido pues puede optar, por un lado, entre un "rico propietario, ajeno á los negocios públicos", por ende, "fiel, casero, monótono", ${ }^{16}$ que no suscite envidias ni recelos - como le sugiere su padre-o, por el otro, el patricio, honorable y sensible, como el alma de ella, joven tan espiritual que no podrá tener más sustituto que Dios: "ya se lo he jurado: 'él ó Dios.' Mi resolucion está tomada [ . . . ". ${ }^{17}$

Esta actitud de la protagonista femenina manifiesta de varios modos los ideales patrióticos de la Nueva Generación; en particular, el fomento de la educación -inclusive y sobre todo de las mujeres - como garantía para el efectivo

${ }^{12}$ Ibid., p. 27.
${ }^{13}$ Ibid., p. 55.
${ }_{14}$ Ibid., p. 12.
${ }^{15}$ Ibid., p. 11.
${ }^{16}$ Ibid., p. 58.
${ }_{17}$ Ibid., p. 56. 
ejercicio de la libertad y, por ende, la renovación de ciertas prácticas sociales - como el casamiento por conveniencia o por imposición de los padres - que los intelectuales románticos identificaban como tradiciones hispánicas retrógradas, inadecuadas para los nuevos tiempos posrevolucionarios. No obstante, se cuelan en el discurso narrativo algunas notas discordantes. El tío de María - quien, por ser clérigo, anciano e ilustrado, aparece como sinónimo de sabio- opina que la "revolucion ha estallado en su madurez", ${ }^{18}$ pero en lo relativo a la expedición al Alto Perú, revela sus preocupaciones - que son sin duda las de los hombres de Buenos Aires- respecto, no del enemigo español, sino de los propios altoperuanos, quienes treinta años antes "se sublevaron en ódio á la raza blanca". Lo que para los nativos bolivianos ha sido una lucha étnica, para los porteños - que se comportan como hermanos mayores muy soberbios-debe ser una lucha por las más "altas razones":

Ellos comprenden la libertad como las Alpacas y las Llamas, para vivir holgados y holgazanes al aire libre de sus cerros. Pero esa no es la libertad de Mayo, que nos exije, trabajo, abnegacion, virtudes. Puede ser muy bien que esos hombres resistan al bien que pretendemos hacerles. En ese caso, hija mia, la guerra puede ser duradera y peligrosa $[\ldots] .{ }^{19}$

La novela de Bartolomé Mitre amplía la gama de roles masculinos pues presenta cuatro tipos, encarnados en cada uno de los varones que forman parte del entorno de Soledad: dos adultos mayores y dos jóvenes, quienes a su vez se contraponen entre sí. El padre, don Pedro, muerto hace años, ha gastado su fortuna a favor de la causa patriota, que en Bolivia - donde está ambientada la historia- ha comenzado en 1809, con una revuelta pronto sofocada. El esposo, don Ricardo, en cambio, no ha aprobado la Revolución, sobre todo, porque le conviene que se mantenga el statu quo para proteger así su cuantiosa herencia obtenida en la explotación de minas de Potosí. Eduardo, quien pretende seducir a Soledad, es el egoísta que mantiene una postura política ambigua, según sus

${ }^{18}$ Ibid., p. 9.

${ }^{19}$ Ibid., pp. 65-67. 
conveniencias. Enrique, por el contrario, culmina el ciclo patriótico iniciado por don Pedro luchando en Junín y Ayacucho, batallas por las que alcanza el grado de capitán.

Las actitudes hacia la Patria de estos varones se corresponden con las que tienen hacia Soledad. El propio autor ha anticipado en el "Prólogo" que ha querido "hacer depender el interes mas del juego recíproco de las pasiones, que de la multiplicidad de los sucesos, poniendo siempre al hombre moral sobre el hombre fisiolójico" ${ }^{20}$ Como ejemplo del cuestionado "hombre fisiolójico", Mitre presenta a don Ricardo y a Eduardo; el primero se muestra vil cuando exige la mano de Soledad (cuarenta años menor que él) a cambio de la protección económica que ella y su madre necesitan tras la muerte de don Pedro y del decomiso de sus bienes "por haber pertenecido á un rebelde", ${ }^{21}$ el segundo, cuando corteja a la joven casada mientras abandona a su prima Cecilia, a quien ha dejado embarazada. Como modelo del "hombre moral", el novelista distingue la protectora paternidad de don Pedro y la valiente magnanimidad de Enrique. Este militar evita que Soledad caiga en la trampa seductora de Eduardo, salva a Cecilia de su intento de suicidio y decide no matar al inescrupuloso en un duelo. En recompensa por todas estas buenas acciones podrá casarse con su amada Soledad cuando ella enviude poco después, mientras que los pecadores - don Ricardo, Eduardo e, incluso, Cecilia— deberán primero arrepentirse para alcanzar luego la paz eterna, el primero, y la felicidad familiar, los dos restantes.

La interpretación que hace Mitre, futuro historiador oficial de Argentina, respecto de las revoluciones hispanoamericanas se manifiesta no sólo en la trama novelesca y en la axiología de las acciones, sino también en la palabra de los personajes. En una conversación sobre noticias referidas a las disputas por Tarija entre la República Boliviana y Argentina (hacia 1826), don Ricardo Pérez rechaza el cambio de estado político porque, arguye, se ha roto la unidad de Bolivia: "cuando todas estas tierras pertenecían al Rey de España, no había estas dispu-

${ }^{20}$ Mitre, op. cit., p. 95. Este autor no vuelve a escribir novelas, sino que se dedica a la historiografía. Su trayectoria se concentra en torno a la política, a través del periodismo, las campañas militares y los cargos públicos. Ocupa la Primera Magistratura durante el periodo 1862-1868.

${ }^{21}$ Ibid., p. 138. 
tas de territorio, todos vivían en santa paz como hermanos [...]. Ah! qué tiempo aquel de los Vireyes! Entonces si se podía vivir, pero la patria ha venido á acabar con todo". Eduardo, sagaz para manipular a su interlocutor, le presenta el beneficio más indiscutible de la Revolución: "De colonos hemos pasado á ciudadanos [,] nos hemos constituido en nación soberana é independiente, los hijos del país ocupan los primeros destinos [...]". .22 Pérez objeta estas razones poniendo a consideración la triste realidad:

[... y yué es lo que hemos ganado? Pasar á ser esclavos de otros tiranos mayores que los que teníamos antes, que disponen á su antojo de nuestras vidas y propiedades [...], y por último ser nación soberana é independiente solo para buscar querellas a nuestros vecinos! Vivimos en medio del desorden, de la pobreza y de la sangre. ${ }^{23}$

El joven reconoce estos males, pero los considera pasajeros (e inevitables, según el movimiento dialéctico de la historia, agregaría Mitre):

Hemos dado ya el primer paso, que era el más difícil, y no debemos considerar el actual orden de cosas sino como transitorio [...]; pero sin embargo, añadió queriendo hacer una nueva concesión, creo que la revolución americana ha sido prematura, y que si se hubiese postergado algún tiempo más se habría ahorrado mucha sangre, y muchos sacrificios. ${ }^{24}$

El personaje resuelve así el debate sobre un tema que, en definitiva, no le interesa mucho. El novelista, en cambio, desvía la atención del lector: la saca del pasado (acerca de la oportunidad de la Revolución) y la guía hacia el futuro, hacia cómo superar las divisiones intestinas y cómo construir una nación verdaderamente libre y progresista. La estrategia de Mitre está sutilmente empleada y se descubre en el hecho de que los miembros de las dos parejas finales - Soledad y Enrique, Cecilia y Eduardo- sean primos entre sí. Aún más, la protagonista re-

\footnotetext{
22 Ibid., p. 121.

${ }^{23}$ Ibid., p. 122.

${ }^{24}$ Ibid., pp. 122 y 123.
} 
flexiona que, si Enrique no se hubiese ido a la guerra, ellos habrían sido felices (don Pedro planeaba casarlos cuando tuviesen edad suficiente): "Yo le habria amado con todo mi corazon, y él tambien me hubiera amado á mi, y entonces no hubiera sentido la necesidad de amar á un extraño". ${ }^{25}$ La endogamia simboliza, entonces, el anhelo colectivo de eliminar las disidencias entre los pueblos hispanoamericanos. La nueva sociedad, como las nuevas familias que constituyen los protagonistas, surgirá de la eliminación de los vicios y la supremacía de la virtud en un proceso inevitablemente doloroso, como el que padece Cecilia: tras el aborto que sufre, especie de castigo por la falta moral cometida (el apuro por mantener relaciones sexuales antes de casarse, como se habrían apurado los criollos en rebelarse, en 1809, antes de estar maduros política y socialmente hablando), recompone su destino con el matrimonio y el nacimiento de su primer hijo. Don Ricardo, antes de morir, también reconoce su error: "he separado lo que Dios habia hecho para unirse; arrastrado por un amor insensato quise unir la juventud á la vejez", ${ }^{26}$ y da su bendición a los enamorados, que es el modo con que el novelista expresa su convencimiento de que la independencia de los pueblos hispanoamericanos es providencial (según la concepción historicista romántica), que el pasado español está definitivamente superado y que las nuevas generaciones obtendrán los beneficios de la libertad y el progreso.

Las consecuencias negativas de los sucesos revolucionarios afloran, curiosamente, en una novela que se escribe durante el periodo de la Organización nacional, después de la derrota de Rosas y del regreso al país de los emigrados políticos. En Una noche de boda (1854), ${ }^{27}$ Miguel Cané presenta un personaje

25 Ibid., p. 145

${ }^{26}$ Ibid., p. 163.

${ }^{27}$ La primera edición aparece en el t. II (setiembre de 1854) de El Plata Científico y Literario. Es reeditada en El Imparcial, Córdoba, 10-18 de setiembre, 1857, en el folletín de La Tribuna, Buenos Aires, $14-18$ de abril, 1858 y ese mismo año, en el t. III de la Biblioteca Americana, con textos de Alejandro Magariños Cervantes. Cané es miembro de la Asociación Joven Argentina, se dedica al periodismo y a la literatura. Gracias a sus viajes por Europa ha dejado páginas muy interesantes sobre el arte italiano y la sociedad europea, en comparación con la sudamericana. Cfr. Beatriz Curia, "Miguel Cané, (1812-1863), primer novelista argentino", en Decimonónica, vol. 4, núm. 1, invierno, 2006. En http://www.decimonica.org. 
contradictorio: Conrado, un militar patriota quien es dominado por la ira cuando se entera de que su amada Atilia se casa con otro, que - para colmo- es español. La joven ha cedido ante las imposiciones paternas y ha roto su compromiso con Conrado, quien - a pesar de ser hijo de un noble castellano - por ella ha abrasado las ideas revolucionarias de Mayo y se ha hecho granadero del regimiento sanmartiniano. El padre de Atilia, también español, ha fingido durante años aceptar aquel noviazgo sólo por miedo a que el patriota lo denunciara por cualquier causa. ${ }^{28}$ Otro de los motivos paternos es la ambición, pues el nuevo pretendiente, Ignacio Rodríguez, tiene una buena fortuna. Atilia, cuyo corazón "está en lucha" con sus deberes filiales, ${ }^{29}$ enfrenta a su marido haciéndole graves acusaciones, las cuales descubren los entretelones vividos en la sociedad argentina después de la Revolución. La joven, tal vez por el imperio de las convenciones sociales, no formula su acusación directamente sino a través del relato de una "historia" que ella dice haber oído en su niñez:

[... entretanto uno de esos pigmeos que al abrigo de la hipocresía y del dobles, saben amontonar caudales inmensos, uno de aquellos que agazapando los altos sentimientos del honor, de la libertad, de la sagrada causa de Mayo, han hecho más males á la patria que todos los ejércitos enemigos, se introdujo en la morada de la joven[,] deslumbró los débiles ojos de sus padres, y procuró comprar el corazón de su hija, empleó para ello todos los medios, todos los ardides [...] la calumnia, la lisonja, la amenaza, la mentira [... todo, todo empleó. ${ }^{30}$

Cané no se detiene a aclarar cuáles son las mentiras con las que Rodríguez ha perjudicado a Conrado; lo que interesa al novelista es plantear claramente esta serie de dicotomías: español, traicionero, cobarde, apátrida, materialista vs. argentino, leal, valiente, patriota, espiritual. La lección moralizadora del novelista surge del desenlace trágico: el recién casado mata a la novia que lo ha rechazado,

${ }^{28}$ Recordemos que muchos españoles fueron deportados e incluso fusilados cuando se les acusó de atentar contra el nuevo gobierno criollo.

${ }^{29}$ Miguel Cané, "Una noche de boda", en "Folletín" de La Tribuna, Buenos Aires, 15 de abril, 1858, p. 1.

${ }^{30} \mathrm{Ibid.}$. "Folletín", 16 de abril. 
Conrado dispara contra el asesino y luego se suicida; el narrador explicita el mensaje: "Los que os reis del corazón, mirad ese grupo. Tres cadáveres solemnizan la boda calculada por los padres de Atilia". ${ }^{31}$ El progreso material ha hecho perder el idealismo de los primeros ciudadanos y en la nación independiente se han multiplicado las máscaras. El patricio se queja de que quienes han impulsado a los jóvenes a pelear por la Patria, luego los repelen como si ser soldado fuera una labor despreciable, mientras que las novias buscan candidatos de mayor fortuna. Conrado, a su regreso de la campaña militar, sólo esperaba recibir de la Patria la "propiedad del corazón", o sea, el amor de Atilia. Decepcionado, asocia la deslealtad de la joven con las traiciones hacia los ideales patrióticos que cometen algunos dirigentes:

-iGloria [...] porvenir, quimeras, Carlos con que nos alucinan para hacernos matar. Nosotros, soldados de la nueva República, pobres niños con corazón y sin cabezas, no sabemos distinguir todo el dobles que encierran las palabras pronunciadas por ciertas bocas; [... l la patria libre, la patria, como la concibieron los padres de 1810, no es esta en que nosotros vivimos Carlos [...]. El cielo sabe que al derramar mi sangre, yo creía fecundar la libertad, y no la licencia, el abuso, ó la tiranía $[. .$.$] . Un pueblo libre, Carlos, no tiene más amo que la ley, y la ley no$ apadrina las ambiciones torcidas $[\ldots]^{32}$

Ni el personaje ni el novelista identifican con precisión a esos malos dirigentes, aunque podemos suponer que se trata de todos aquellos que se disputaron el poder después del derrocamiento de Rosas, y que produjeron la separación del Estado de Buenos Aires del resto de la Confederación Argentina (1852-1860). Cané escribe desde su presente histórico y las urgencias políticas le imponen esa interpretación del pasado tan melancólica y pesimista.

${ }^{31}$ Ibid., "Folletín", 18 de abril.

${ }^{32}$ Loc. cit. 


\section{LA GESTA SANMARTINIANA}

En 1857 un autor hoy totalmente desconocido, Manuel Romano, publica El isleño: episodio de la guerra de la Independencia, con la intención de que no caiga en el olvido "uno de esos brillantes episodios de nuestra historia": 33 la batalla de San Lorenzo. La centralidad de este "episodio" se infiere de la descripción minuciosa del combate, caso único en la novelística romántica argentina. Julián Corbera, el isleño, ama a Clara, pero el padre de ésta no quiere aceptarlo porque el joven es huérfano, es decir, sin una familia, sin un padre, que garantice un origen digno. No obstante, pronto surgen dos defensores-padres para Julián: el párroco del convento de San Lorenzo, quien lo ha criado, y el por entonces coronel San Martín, quien destaca la valentía del joven bajo sus órdenes durante el combate del 3 de febrero de 1813. El ritmo narrativo pone en paralelo ambas situaciones: por un lado, el proceso de convencer al padre de Clara para que acepte a Julián y, por otro, el avance de la escuadrilla española por el río Paraná. El isleño es un joven decidido: "Con el nombre de Clara en el corazón, y con la espada en la diestra, yo mostraré que soy siempre el hombre fuerte que sabe posponer el amor al honor y al deber" ${ }^{34} \mathrm{El}$ desenlace, como es de esperar, reúne las dos victorias con la presencia de San Martín, vencedor, en la boda de los jóvenes patriotas.

El resto de la gesta sanmartiniana aparece en la novelística de Vicente Fidel López: Capitán Vargas, escrita en 1846, inconclusa y todavía inédita, y La Loca de la Guardia, publicada primero como folletín en El Nacional, de Buenos Aires (entre junio y agosto de 1882) y luego reeditada con variantes, en un volumen a cargo de Carlos Casavalle (1896). Dado que ésta no comparte el contexto histórico-políico de las anteriores novelas comentadas, nos limitaremos a Capitán Vargas, conservada en dos manuscritos de la Colección de los López, en el Archivo General de la Nación (Buenos Aires). ${ }^{35}$

33 Romano, op. cit., p. 3.

${ }^{34}$ Ibid., p. 62.

${ }^{35}$ Cfr. Hebe B. Molina, "Política e historia sudamericana en dos novelas de Vicente Fidel López", en VIII Jornadas Andinas de Literatura Latinoamericana, 2008, CD ROM, Santiago, Universidad de Chile, 2008. 
En la correspondencia privada entre el novelista y su padre, don Vicente Alejandro López y Planes, se halla información acerca de que el texto ha sido escrito en Montevideo hacia 1846, después del exilio santiaguino (1841-1845) del joven Vicente Fidel. ${ }^{36}$ La novela toma como encrucijada un periodo complejo de la historia chilena, entre 1810 y 1814, cuando a las luchas por la Independencia se suman las disputas internas entre O'Higgins, por un lado, y los hermanos Carrera, por otro, y cuando las fuerzas militares chilenas resultan insuficientes para frenar a los realistas y deben recurrir al auxilio argentino. Hay, por lo tanto, en la estructura narrativa una serie imbricada de oposiciones de índole geopolítica: realistas versus sudamericanos, chilenos versus argentinos, seguidores de los hermanos Carrera versus seguidores de O'Higgins y Mackenna. Las preferencias ideológicas del autor-narrador son remarcadas por el elemento diegético: en la trama, los personajes puramente ficticios se van relacionando sucesivamente con los protagonistas de las acciones políticas más convenientes, según la postura del novelista-historiador. Teresa, huérfana protegida por los Carrera, se enamora de su vecino Manuel Vargas. También Juan José Carrera desea a la atractiva joven y, por ello, pelea cuerpo a cuerpo con Vargas. Éste se enrola en las filas patriotas de O'Higgins y por su valentía alcanza el grado de capitán; la enemistad con los Carrera se extiende entonces al plano político. El amor por Teresa, objeto de deseo de ambos antagonistas, se convierte en símbolo de la lucha intestina por el poder, que complica la liberación definitiva del yugo español. Para no caer en manos de su enemigo, la mujer se refugia en casa de Juan José Passo, el embajador argentino quien, junto con el comandante Juan Gregorio de Las Heras, planifica las acciones por seguir ante el derrocamiento del director supremo Lastra que ha encabezado José Miguel Carrera. La diplomacia y la estrategia político-militar son puestas al servicio de un proyecto extraordinario: el cruce de los Andes por parte de un ejército cuantioso, al mando de

${ }^{36}$ Este autor puede ser considerado como el primer teorizador literario argentino, aunque sus preferencias personales se dirigen hacia la historiografía, la economía política, los estudios etnográficos y lingüísticos, entre otras disciplinas. Polemiza con Mitre a favor de los testimonios orales y de la reconstrucción imaginaria del pasado cuando el historiador carece de pruebas documentales. 
José de San Martín; proyecto que deberá salvar a Chile, como es resguardado el amor de Manuel y de Teresa en el hogar del embajador argentino.

Passo y Las Heras sostienen un extenso diálogo (cap. XIII) en el que puede analizarse no sólo la postura historiográfica del novelista, sino también sus reacciones afectivas ante la realidad sociopolítica en que vive. López inventa un Passo pesimista y volteriano, muy preocupado tanto por las envidias entre los pueblos sudamericanos que impiden la unión de fuerzas contra los godos, como por la difamación de las personas y el peligro de un falseamiento de la historiografía futura, que desvirtúe la acción desinteresada de los patriotas. En una de las revisiones, el novelista agrega dos folios a esa conversación, destinados a explicitar la interpretación histórica que justificaría esa visión pesimista. En síntesis, Passo arguye que todos los problemas políticos son consecuencia directa del régimen español; este sistema colonial e inquisitorial, basado en la sujeción ciega y en el fanatismo religioso, ha mantenido inculto al pueblo y, por consiguiente, éste cae fácilmente bajo el dominio de caudillos y tiranos, y de las envidias nacionalistas. Siguiendo la dialéctica hegeliana, López -siempre a través de Passoavizora que, después del periodo retrógrado de la Colonia, vendrá otra época, también viciosa, "qe. no tendrá mas dios q q $^{\mathrm{e}}$ el egoismo y la individualidad". ${ }^{37} \mathrm{No}$ obstante, y gracias al influjo benéfico de los libros de otros países - como Francia, Inglaterra y Estados Unidos, que no han tenido una Inquisición tan poderosa como la de España - y de "la enseñanza sangrienta de los acontecimientos" que se prevén, surgirán luego los "hombres nuevos" que rescatarán y continuarán la obra de los primeros patriotas; serán "hombres escogidos", es decir, hombres ilustrados, pues son los únicos que pueden actuar con libertad, a pesar de todos los sacrificios que la situación nacional les exija. ${ }^{38}$ Con este razonamiento, López plantea no sólo un problema pasado sino sobre todo una cuestión de su presente: Argentina todavía no ha superado esas consecuencias nefastas del régi-

37 Vicente Fidel López, Capitán Vargas, Colección de los López, Archivo General de la Nación, Buenos Aires, ms. núm. 5253, f. 142, agregado 1. Preparamos una edición crítica de estos manuscritos.

${ }^{38}$ Ibid., f. 142, agregado 2. 
men colonial pues un tirano, Juan Manuel de Rosas, mantiene ese mismo sistema de dominación casi sin variantes, para beneficio particular. ${ }^{39}$

Después de la batalla de Caseros, en 1852, López regresa a Buenos Aires pero, por disidencia con otros porteños, se instala nuevamente en Montevideo desde donde publicará la versión definitiva de La novia del hereje o La Inquisición de Lima (1854-1855), novela histórica ambientada en la Lima colonial, en la que renueva su crítica contra todo tipo de despotismos. Completará su magisterio en los tres tomos de La revolución argentina: su origen, sus guerras y su desarrollo político hasta 1830 (1881), entre otros títulos de su cuantiosa producción historiográfica.

\section{LA PERSPECTIVA FEMENINA}

Las victorias militares y la gloria personal de los héroes interesan a los escritores varones, no así a las novelistas que tratan este tema. Juana Manuela Gorriti, a pesar de ser hija de José Ignacio de Gorriti, un destacado políico y general de las huestes de Martín Miguel de Güemes, dedica sólo uno de sus numerosísimos relatos al tema de las luchas independentistas - El pozo del Yocci (1869-1870) y lo hace para abominar de las guerras civiles que han afectado a millares de argentinos, entre ellos la propia escritora, como si no le interesasen los tiempos de gloria tanto como los de dolor.

39 En las opiniones de Passo se manifiestan los miedos del propio novelista respecto del reconocimiento que obtendrá y del lugar que como historiador y político le corresponderá en la historia argentina; también se revela la decepción de López ante la poca adhesión de los chilenos a las ideas progresistas que él, Sarmiento y otros compatriotas exiliados promueven a través del periodismo y la cátedra universitaria; desinterés que se basaría en su condición de argentinos.

${ }^{40}$ Esta novela aparece por primera vez en La Revista de Buenos Aires, ts. XX a XXII, entre 1869 y 1870. Posteriormente, es incluida en Panoramas de la vida (1876), edición que citamos. Juana Manuela nace en Salta, en el norte de Argentina; con su familia se refugia en Bolivia, donde se casa con el político y militar Manuel Isidoro Belzu. Después se instala en Lima, a la que considera su segunda patria. Finalmente radica en Buenos Aires, donde fallece. Publica 124 narraciones (cuentos y novelas cortas). 
El cambio de perspectiva genérica se advierte desde el primer capítulo de esta novela ya que la acción comienza por una derrota: la retirada de las tropas realistas, desde Jujuy hacia Bolivia, por el abra de Tumbaya, bajo el fuego de los "guerrilleros argentinos", ${ }^{41}$ retirada que significará para las familias de los españoles el abandono de sus hogares. En esa situación penosa, un joven patricio, conocido sólo por el nombre de Teodoro - porque su padre, español, ha renegado de él-, se lanza sobre los realistas para vengar la deshonra de su hermana. Esta acción excede el ámbito privado porque lo que Teodoro rechaza no es tanto el amorío oculto como la condición de "godo" del amante: aunque éste le ha asegurado su afecto incondicional por Isabel, el hermano responderá: "ieras un godo Bendito sea Dios, que me trae á tiempo para evitar, matándote, tu alianza, mas vergonzosa que la misma deshonra!" ${ }^{22}$ Veinticinco años después, en ese mismo desfiladero se enfrentarán Felipe Braun, de la Confederación peruano-boliviana, y Alejandro Heredia, de la Confederación argentina. Si bien el escenario es el mismo, el valor moral de la lucha no lo es: "aquella era una guerra santa; esta es una guerra fratricida. ¿Qué hay de común entre la una y la otra?" ${ }^{43}$ se pregunta un soldado que ha participado en ambas.

El contraste de valoración de varones y mujeres respecto de las guerras patriotas se observa más nítidamente en María de Montiel: novela contemporánea (1861), novela escrita por Mercedes Rosas de Rivera, pero publicada con el seudónimo M. Sasor. María de Montiel es hija de María Teresa Pérez, una mujer que se ha rebelado contra su padre español y ha abandonado a su madre querida por amor a un patricio; separación familiar que le provoca un dolor tan persistente que la conduce a la muerte poco después de dar a luz a María. Mientras la niña crece, su padre - don Miguel Montiel, veterano de la defensa porteña contra los invasores ingleses-entabla amistad con el joven Leoncio de C., quien

${ }^{41}$ Juana Manuela Gorriti, "El pozo del Yocci", en Panoramas de la vida: colección de novelas, fantasías, leyendas y descripciones americanas, pról. de Mariano Pelliza, Buenos Aires, Imprenta y Librerías de Mayo, 1876, t. I, pp. 349-450; p. 350.

${ }^{42}$ Ibid., p. 365

${ }^{43}$ Ibid., p. 395 
en 1812 se incorpora al Ejército Libertador, participa en las batallas de Tucumán, Salta y Chacabuco; con el grado de coronel, en 1824 regresa a Buenos Aires gracias a una licencia de pocos meses. El amor mutuo entre María y Leoncio nace inmediatamente una noche en la que ella viste de celeste y blanco como galantería hacia el patricio; los enamorados se comprometen antes de que el militar deba volver a su regimiento. El valiente patriota muere en Ayacucho, es decir, en la última batalla de la gesta independentista. La trama busca, al parecer, ejemplificar un refrán que se repite varias veces en el texto novelesco: "El hombre propone y Dios dispone". Dios dispone que María se recupere de tan grande dolor y se case con Jorge Harris, joven amigo de la familia Montiel, quien ha amado a María con timidez y abnegación desde antes de que la joven conociese a Leoncio. Mientras María y el militar disfrutaban su noviazgo y padecían la separación forzosa, Jorge viajaba a Europa para recuperarse de una enfermedad causada por sus penas de amor; regresa a Buenos Aires cuando se entera de la viudez de su amada. Si bien existe la posibilidad de que el argumento esté tomado de un caso verídico, ${ }^{44}$ no deja de llamar la atención el contraste entre Leoncio y Jorge: uno, valiente y patriota hasta dar la vida; el otro, indeciso y enfermizo. Más curioso aún es el desenlace, que beneficia al enamorado que podríamos calificar como el más egoísta por cuanto se muestra indiferente ante los problemas de la Patria. Esta axiología se sustenta en la valoración de la gesta bélica que sostiene la propia novelista y que se evidencia en la adjetivación con que se refiere a la guerra. Si para los personajes militares la acción en la que participan es una "cruzada", "un hecho beroico", ${ }^{5}$ por la que sacrifican sus relaciones afectivas, para los personajes femeninos es una "maldita guerra" ${ }^{\text {"46 }}$ porque aleja y mata a sus hombres.

${ }^{44}$ En el prólogo, la autora explica: "Escribo esta novela, para reunir en ella algunos recuerdos que me son gratos. [...] El poco interés que presenta mi novela es la originalidad, que muchos de los personajes que figuran han existido en Buenos Aires". M. Sasor [Mercedes Rosas de Rivera], María de Montiel, novela contemporánea, Buenos Aires, Imprenta de "La Revista", 1861, p. 5. Mercedes es hermana del polémico gobernador de Buenos Aires, Juan Manuel de Rosas.

${ }^{45}$ Ibid., pp. 11 y 12.

${ }^{46}$ Ibid., pp. 51, 72, 92, 114. 
Hebe Beatriz Molina

Algunas declaraciones de Leoncio explicitan el dilema que enfrenta cada patricio:

Antes de conocerte sólo pensaba en conquistar la libertad de mi patria: pero ahora mis deseos están en lucha con mi amor;

iDios mío! Una niña, una mujer ha cambiado mi ser, y el León de las Batallas, como me llaman mis compañeros, está reducido a un ser sin valor moral. Pero no, María, una vez en mi puesto, yo recobraré mi nombre, tú no podrías amar a un cobarde $[. .$.$] . La gloria que reciba caerá sobre mi amada, y los laureles que yo re-$ coja serán puestos a tus pies $[\ldots] .^{47}$

\section{CONCLUSIONES}

La temática de las luchas independentistas ha generado dos tipos de novelas históricas según las motivaciones personales de los autores: por una parte, la novela dramática y moralizadora -El capitán de Patricios, Una noche de boda, El pozo del Yocci y María de Montiel-, en la que el patriota debe elegir entre la Patria o la amada, la protagonista padece tanto por las imposiciones familiares como por la participación del amado en esos violentos combates, y el lector recibe una advertencia acerca de cuáles son las únicas acciones moralmente buenas que pueden aceptarse en la nueva nación; por otra parte, la novela didáctica -Soledad, El isleño y Capitán Vargas-, a través de la cual el novelista privilegia la lección de historia: los hechos se encadenan dialéctica e inevitablemente, superando cada uno al anterior; y sólo los hombres patriotas y más decididos logran toda clase de triunfos.

El género novela, gracias a su matriz idealista y romántica, dramatiza la opción sagrada que se proclama en el Himno nacional argentino: "coronados de gloria vivamos, o juremos con gloria morir". Pero por su rasgo distintivo -idealización de sucesos cotidianos para fortalecer y promover las buenas accionesse concentra en los asuntos del presente y descuida los del pasado. El componente sentimental "amor a la mujer" coadyuva a resaltar las cualidades viriles de

${ }^{47}$ Ibid., pp. 87, 90 y 91. 
los patricios, quienes sacrifican su interés personal en el altar de la Patria.Y Yes, precisamente, en esta valoración del sacrificio masculino donde se advierten diferencias axiológicas (valorativas) entre los escritores y las novelistas: ellos destacan el patriotismo de sus personajes varones y la abnegación de las amadas, mientras que ellas lamentan las separaciones amorosas y familiares que tales luchas han provocado. Dos miradas distintas sobre la misma Patria: la Patria-padre y la Patria-madre.

Recibido: 21 de septiembre, 2010. Aceptado: 21 de junio, 2011

BiBLIOGRAFÍA

Cané, Miguel, "Una noche de boda", en "Folletín" de La Tribuna, Buenos Aires, 14, 15, 16, 17 y 18 de abril de 1858, pp. 1.

Curia, Beatriz Elena, "Amalia, novela histórica", en Revista de Literaturas Modernas, núm. 16, 1983, pp. 71-81. , "Miguel Cané (1812-1863), primer novelista argentino", en Decimonónica, vol. 4, núm. 1, invierno, 2006. En http://www.decimonica.org.

,"Para una refutación del fundamentalismo machista: María de Montiel, de Mercedes Rosas de Rivera", en Palabra y Persona, segunda época, año III, núm. 4, Buenos Aires, Centro Argentino P.E.N., Internacional, abril, 2008, pp. 75-86.

GłowINSKI, Michat, "Theoretical Foundations of Historical Poetics", trad. de Bruno Braunrot, en New Literary History, vol. 7, núm. 2, winter, 1976, pp. 237-245. 
Gorriti, Juana Manuela, "El pozo del Yocci", en Panoramas de la vida: Colección de novelas, fantasías, leyendas y descripciones americanas, pról. de Mariano Pelliza, Buenos Aires, Imprenta y Librerías de Mayo, 1876, t. I, pp. 349450.

GutiéRrez, Juan María, El capitán de Patricios, Buenos Aires, Imprenta del Siglo, 1864. En www.bibnal.edu.ar/webpub/digital.asp.

IANes, Raúu, De Cortés a la buérfana enclaustrada: la novela bistórica del romanticismo hispanoamericano, Nueva York, Peter Lang, 1999.

López, VICenTe Fidel, Capitán Vargas, Colección de los López, Archivo General de la Nación, Buenos Aires, ms. 5253 y 6884.

, "Carta-prólogo", en La novia del hereje o La Inquisición de Lima, Buenos Aires, Imprenta de Mayo, 1854, pp. 3-10. , Curso de Bellas Letras, Santiago de Chile, Imprenta del Siglo, 1845 .

MITRE, BARTOLOMÉ, Soledad: novela original, nota preliminar de Juan Millé y Giménez, Buenos Aires, Universidad de Buenos Aires, Facultad de Filosofía y Letras, 1928, pp. 89-168.

Molina, HeBe BeATRIZ, Como crecen los hongos: la novela argentina entre 1838 y 1872, Buenos Aires, Teseo, 2011 [en prensa].

"Políica e historia sudamericana en dos novelas de Vicente Fidel López", en VIII Jornadas Andinas de Literatura Latinoamericana, 2008, CD ROM, Santiago, Universidad de Chile, Centro de Estudios Culturales Latinoamericanos, 2008.

, "Un nacimiento acomplejado: justificación de la novela en el contexto decimonónico argentino", en Alba de América, vol. 25, núms. 47-48, 2006, pp. 457-466.

, "Una poética argentina de la novela: Vicente Fidel López (1845)", en Hofstra Hispanic Review, núms. 8-9, Nueva York, verano-otoño, 2008, pp. 18-32.

, "Vaivenes de la novela argentina: entre la teoría, la escritura y la recepción (1838-1872)", en Decimonónica, vol. 5, núm. 2, verano, 2008, pp. 33-48. En www.decimononica.org. 
Romano, Manuel, El isleño: episodio de la guerra de la Independencia, Buenos Aires, Imprenta Americana, 1857.

Rosas de RIvera, Mercedes [M. SASOR], María de Montiel, novela contemporánea, Buenos Aires, Imprenta de "La Revista", 1861.

UnzUeTA, FeRnANDO, La imaginación histórica y el romance nacional en Hispanoamérica, Lima-Berkeley, Latinoamericana Editores, 1996. 